\title{
HABILIDADES DE GERENCIAMENTO E DE EMPREENDIMENTO NA PROFISSÃO DE BIBLIOTECARIO E CIENTISTA DA INFORMAÇÃO
}

\section{Irene Wormell}

\begin{abstract}
Resumo
A informação pode ser considerada tanto um processo como um produto. É também considerada como uma mercadoria de valor econômico. Partindo deste pressuposto, uma pesquisa foi realizada em organizações ou empresas que oferecem e taxam serviços de informação. A partir da descrição dos dados, um manual foi elaborado, visando ajudar alunos e profissionais no empreendimento em serviços de informação.
\end{abstract}

\section{Palavras-Chave}

Informação-Mercadoria; Informação-Processo; Serviços de Informação.

\section{Desenvolvimento de papéis e funções}

O papel clássico do bibliotecário tem sido sempre o de guiar e aconselhar usuários nas suas buscas por informação. Qualquer que seja o nível das tecnologias disponíveis na área de Biblioteconomia e Ciência da Informação, o trabalho do bibliotecário tem sido mediar provedores, sistemas e usuários da informação. Tradicionalmente, esta tem sido uma função didáticoeducativa, caracterizada pelo trabalho de um indivíduo com um profundo e criterioso conhecimento da natureza do ambiente informativo.
O fato de os conceitos de informação terem-se desenvolvido solidamente através da história da humanidade, provocou, igualmente, uma tentativa de fazer o mesmo no que diz respeito aos papéis e funções do bibliotecário como profissional de informação. Tais profissionais têm desenvolvido suas atividades em ambientes que exigem mudanças radicais em seus papéis tradicionais. Há uma necessidade crescente de reduzir o aspecto voltado para a custódia, presente no trabalho da biblioteca e abandonar a atitude passiva da profissão.

Atualmente, o compartilhamento de dados 
bibliográficos, os catálogos em linha e as facilidades crescentes de redes de informação, têm implicações importantes para a Biblioteconomia e caracteriza uma era em que profissionais "inábeis" perderão espaços para usuários "hábeis". As habilidades de recuperar, organizar e armazenar informação de fontes impressas ou eletrônicas não mais servirão como base para os serviços de informação e bibliotecas, pois a natureza da disseminação e consumo da informação está mudando. O usuário agora requer um tipo de informação filtrada e analisada em detalhes. Esta informação precisa ser "empacotada" de uma forma fácil de ler, fácil de entender e, finalmente, fácil de aplicar.

Existem, relativamente falando, poucos profissionais de informação cujo trabalho principal é prover outros profissionais com informação qualitativa, isto é, uma categoria de metaprofissionais que agregam habilidades de busca de informação ao desenvolvimento de sistemas. O papel do mediador entre o provedor de informação e usuários sugere a função de um "catalizador", assim como a informação científica o é para posteriores pesquisas no campo intelectual.

Nas atividades e conexões com a FID, assim como em outros projetos internacionais, temos tido a oportunidade de considerar as maneiras pelas quais nossos colegas descrevem seus papéis e funções (Wormell, 1995). São muitas as situações e estruturas de trabalho e, apesar disso, há um núcleo de novos e emergentes papéis e funções que são descritos de diferentes maneiras. Em resumo, o profissional de informação de hoje, precisa:
- facilitar o uso da informação

- navegar entre sistemas de conhecimento e fontes de informação

- oferecer consultoria e aconselhamento para problemas de informação

- examinar e oferecer um ótimo gerenciamento de recursos de informação

- oferecer serviços de tradução entre várias línguas

- traduzir sistemas técnicos e culturais entre si

- transformar dados e favorecer o fluxo de dados entre sistemas

- conectar contextos sociais e culturais

- educar/treinar os usuários

- prover esclarecimentos sobre recursos de informação

- oferecer suporte às políticas de informação para as estratégias da organização

Estes papéis e funções profissionais são emergentes e estão todos ligados ao usuário ou ao trabalho com profissionais de tecnologias da informação (Figura 1- página ao lado).

Assim, o conceito de informação multifuncional está baseado na construção de pontes entre dois mundos: o primeiro, o mundo do desenvolvimento de sistemas baseados nas tecnologias da informação e o segundo, o mundo que necessita explorar a informação produzida em tais sistemas (Figura 2 - página ao lado).

Estes dois modelos em separado podem ser integrados em uma estrutura unificada que identifica o novo profissional da informação. Tais 
Figura 1: Natureza híbrida do novo profissional da informação

\begin{tabular}{|c|}
\hline USUÁRIO \\
\\
PROFISSIONAL DE \\
TECNOLOGIA DA \\
INFORMAÇÃO \\
\end{tabular}

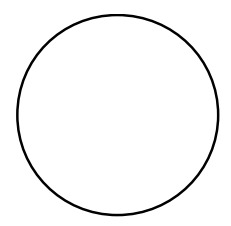

Figura 2: O desenvolvimento de sistemas de informação com base em uma equipe de especialistas

PROFISSIONAL DE


modelos destacam o relacionamento entre os diferentes tipos de papéis que podem ser preenchidos pelos profissionais de informação. Eles igualmente enfatizam a natureza híbrida do trabalho com o gerenciamento da informação.

Adicionalmente, tais modelos ressaltam a importância em reconhecer o papel dos arquite- 
tos, desenvolvedores e construtores de partes específicas do sistema de informação. Cada uma destas partes exige um tipo de especialidade, sendo importante que todos estes especialistas trabalhem em conjunto, utilizando inteiramente suas habilidades, enquanto respeitam as competências e o conhecimento dos demais. A história nos lembra que muitas catedrais, belamente desenhadas, caíram ao chão por falhas arquitetônicas ou de construção. Assim, também deve haver muitos sistemas de informação que não funcionam efetivamente devido a falhas de design ou de representação de formatos. Os grupos envolvidos no desenvolvimento de sistemas de informação, geralmente carecem de algumas habilidades necessárias para que cada papel seja desempenhado de forma adequada.

$\mathrm{Na}$ área de Ciência da Informação, a maior atenção tem sido dada para questões tecnológicas. Até recentemente, problemas de conteúdo têm sido negligenciados. A dominante visão técnica e a perspectiva tecnológica dos problemas de informação não têm sido equilibradas em relação à contribuição de profissionais de outras disciplinas.

\section{Identificação profissional}

Os profissionais de Biblioteconomia e Ciência da Informação que são hábeis na organização, armazenagem e recuperação da informação poderiam oferecer assistência aos usuários assim como àqueles que planejam, desenvolvem $\mathrm{e}$ constroem sistemas de informação. O papel que tais profissionais escolhem nestes processos depende das suas experiências e habilidades pessoais, assim como da competência técnica, da po- sição na organização e outros fatores.

Para criar novas gerações de profissionais é necessário promover iniciativas e explorar perspectivas internacionais e históricas no campo de informação. Uma maneira de realizar tal intento é compartilhar a história dos pioneiros com as novas gerações de profissionais e com os recémchegados, pois isso irá ajudá-los a perceber as mudanças atuais sob uma perspectiva de evolução, construindo pontes entre as gerações e configurando um senso de continuidade, que permita que os profissionais de informações tenham uma auto-imagem baseada em papéis e funções clássicas.

Apesar de a importância da informação não ser ainda reconhecida de modo amplo (nem em negócios nem na sociedade em geral), há uma crescente conscientização sobre suas potencialidades, assim como sobre seu gerenciamento como um "quarto recurso". Nesse sentido, além dos três recursos clássicos para a produção: trabalho, capital e matérias primas, a literatura voltada para negócios está focalizando intensamente os recursos de informação. No entanto, o maior interesse para a exploração de recursos de informação para o benefício da sociedade e negócios, está atualmente concentrado no uso das modernas tecnologias da informação.

Junto com este desenvolvimento, naturalmente o mercado tradicional de produtos e serviços de informação está igualmente em mudança, sendo que seus valores são medidos mais e mais em relação aos novos negócios, à política e aos objetivos sociais.

Inf.Inf., Londrina, v. 4, n. 1, p. 07-16, jan./jun. 1999 
Agilidade, flexibilidade e espírito de empreendimento

A disponibilidade de informação na sociedade moderna exige novas habilidades dos profissionais da área de Biblioteconomia e Ciência da Informação, assim como novas competências para que estes possam adicionar valor aos seus produtos e serviços e oferecê-los eficientemente ao mercado. Como condição básica, estes profissionais devem conhecer seus mercados de atuação o mais profundamente possível e estarem familiarizados com os desenvolvimentos e as necessidades de informação, a fim de desempenharem um papel competitivo no atual mercado de informação.

Com referência à investigação do NORDINFO-BLR\&DD (Wormell, 1996) e outros estudos e pesquisas neste tópico, os seguintes elementos são considerados como os mais importantes no desenvolvimento de produtos e serviços com valor agregado:

- a especialidade do pessoal que trabalha no provimento de serviços e produtos de informação

- a rapidez no serviço

- a qualidade do serviço

- a qualidade do produto

- o impacto da fama do produto ou serviço

- "bons" recursos de informação

Desta forma, para responder às demandas crescentes de uma parte dinâmica da sociedade, é necessário ter em agilidade, flexibilidade e espírito empreendedor no campo de Informação, particularmente aqueles profissionais que atuam no setor público. Um fato amplamente reconhecido é que os serviços gratuitos e públicos, derivados da atividade de uma grande parte de bibliotecários e cientistas da informação, são difíceis de serem transformados e redirecionados a curto prazo. Outro desafio que se apresenta é o de gerenciar os recursos (muitas vezes limitados) para atender as demandas dinâmicas de grupos de usuários acostumados à rapidez, estética e simplicidade do acesso às informações eletrônicas. Além disso, há uma imensa necessidade provinda do atual mercado de informações, que oferece várias formas de serviços de informação, cada qual tendo objetivos e conceitos diversificados do que seja mesmo um "serviço", que possa vir ao encontro das demandas de vários grupos de usuários.

Os cortes orçamentários e as políticas voltadas para "o máximo pelo mínimo de investimento" exigem que os serviços dos profissionais de Biblioteconomia e Ciência da Informação (incluindo aqueles que atuam no setor privado) sejam mais efetivos e eficientes na disseminação e divulgação de seus serviços e produtos. A demanda por uma maior responsabilidade e um exame mais cuidadoso no uso de recursos levam os gerentes a repensarem suas orientações quanto ao orçamento e planejamento para o suprimento de informação dentro de suas empresas. A introdução de mecanismos para a cobrança interna tornou-se um dos métodos mais comuns para tornar o cenário de suprimento e demanda de informação mais claro, assim como para o registro da freqüência de uso dos vários tipos de recursos de informações em diferentes setores da organização. Em alguns casos, as empresas 
escolhem desativar, reduzir ou mesmo não criar qualquer serviço de informação interno, contratando serviços externos para o provimento de informação que venha ao encontro aos seus propósitos de negócios.

Dessa forma, as oportunidades para os serviços de informação com base na cobrança de taxas estão se configurando e se fortalecendo, ao mesmo tempo em que há um desafio para as pessoas que trabalham no campo da Biblioteconomia e da Ciência da Informação. Exigem-se novos modelos e padrões para os serviços de informação, para os quais se deve desenvolver um conjunto de novas habilidades e se devem estabelecer negócios próprios, tendo em vista o provimento de informação.

\section{Como aprender tais habilidades}

Com vistas em estruturar o desenvolvimento de novas habilidades e competências para os profissionais de Biblioteconomia e Ciência da Informação, a fim de que estes possam prover serviços especiais para empresas de qualquer porte e comunidades de negócios locais, esta autora iniciou um projeto junto ao Nordic Research Council for Scientific Information (NORDINFO) e a British Library - Research and Development Department (BLR\&DD). Em primeiro lugar, reconheceu-se a carência de materiais orientados para a discussão e o estabelecimento de serviços de informação taxados, sendo que esta iniciativa objetivou compilar um amplo e prático guia para a descrição de experiências e de conhecimentos práticos sobre este assunto, com base naqueles profissionais que estão sendo bem sucedidos na prática do oferecimento de consultoria e de intermediação de informação, e no gerenciamento de serviços e produtos de informação que visam lucros.

Considerando alguns "exemplos de sucesso" no mercado europeu, o projeto objetivou mapear tais habilidades, competências, técnicas e estratégias de maneira a identificar as fontes de tais experiências e os fatores-chave para o sucesso e sobrevivência em uma época de transição e de mudanças radicais, tanto na profissão, como no mercado de informação.

Esta pesquisa foi realizada por uma equipe integrada por profissionais da Dinamarca, Inglaterra e Suécia, cuja metodologia de trabalho incluiu: 1) revisão de literatura; 2) pesquisa de campo - com questionários enviados/recebidos via correio; 3) entrevistas e 4) análise e descrição dos resultados.

O questionário foi “desenhado" pelos membros da equipe, e uma pequena amostra do universo de serviços de informação taxados foi selecionada para um pré-teste, permitindo ajustes no instrumento de coleta de dados. Neste processo de seleção, considerou-se cuidadosamente o fato de que, na Europa, existe um número significativo de serviços de informação taxados, onde o conceito de "sucesso" não é obter lucros mas assegurar o provimento de informações para a pesquisa, o desenvolvimento regional ou outros objetivos da organização.

Os resultados desta investigação foram então analisados e filtrados por um grupo internacional de consultores de informação. Mais tarde o material foi reestruturado e ampliado e pu- 
blicado como um livro para ser usado na educação e treinamento de profissionais da área de Biblioteconomia e Ciência da Informação ${ }^{1}$. Desta forma, o livro pretende suprir a carência de material didático para estudantes nestas áreas, dentro deste assunto emergente na área de serviços profisssionais voltados para a distribuição de informação. Este livro oferece um panorama abrangente e prático para o estabelecimento e desenvolvimento deste tipo de negócio, que inclui a importância de haver estratégias sólidas para o estabelecimento de preços; a necessidade de se impor ao mercado; a importância de ser pró-ativo e criativo no oferecimento de produtos e serviços; a projeção de uma imagem de credibilidade e o conhecimento das estruturas legais envolvidas nos produtos e serviços oferecidos, além de tópicos, técnicas e "dicas" úteis para aqueles que desejam envolver-se nesta área. Além disso, este manual sugere a necessidade de um pensamento e planejamento estratégico para o desenvolvimento de serviços de informação taxados, assim como relaciona algumas experiências de pessoas que já realizam tais trabalhos na prática, o que pode ser um incentivo a mais para os interessados. No entanto, a experiência prática tem demonstrado que muitos dos "empresários" neste campo falham em suas iniciativas de se tornarem consultores ou intermediários de informação, por não possuírem um conhecimento sólido e pragmático da indústria da informação, da atividade de intermediação da informação e da profissão de consultor em particular.

\footnotetext{
${ }^{1}$ WORMELL, Irene. Critical success factors for fee-based information services. Helsinki : NORDINFO, 1996. 134 p. (NORDINFO Publication, 36). ISBN 95153-1018-0
}

\section{Fatores-chave para o sucesso}

O trabalho de investigação conjunto entre a NORDINFO e a BLR\&DD concluiu que não existe ainda um padrão de desempenho ou medidas de avaliação para os serviços de informação taxados. No entanto, certos fatores chave geram, tais como as habilidades do pessoal envolvido, uma base financeira segura, um marketing apropriado, uma postura pró-ativa e criativa a fim de projetar uma imagem de credibilidade, e a necessidade de entender as estruturas legais que envolvem este tipo de trabalho.

Os entrevistados confirmaram a hipótese original da investigação, na qual se afirmava que o setor de serviços de informação taxados é recente, e cujo mercado é ainda inexplorado, pois os clientes ainda não foram alertados dos serviços disponíveis. Neste sentido, tais serviços não encontram ainda competidores e por isso não se pode dizer que sejam "orientados para um mercado". As entrevistas que se seguiram, assim como os seminários e pesquisas, buscaram complementar e expandir os temas tratados.

No que diz respeito aos valores/preços praticados, estes parecem ter um papel duplo; por um lado, são usados como um mecanismo para alocar recursos e, por outro, como um mecanismo para "recuperar" alguns destes custos. Há uma crítica em relação à política de "recuperação de custos", pois esta é considerada de curto prazo e não orientada para o futuro e para planejamento a longo prazo. Uma vez que o mercado para os profissionais de Biblioteconomia e Ciência da Informação está mudando rapidamente, é importante estabelecer políticas para o estabele- 
cimento de preços de serviços, considerando-se o porquê e os objetivos da cobrança de tais valores. Em termos gerais, uma política possível para os serviços comerciais de informação no setor privado precisa estar sintonizada com os objetivos de 'recuperação de custos' assim como com a alocação de recursos em bases estratégicas para o oferecimento de novos serviços.

Todavia, para o setor público, os serviços de informação taxados têm sido definidos sob um conjunto diferenciado de valores, que vão desde razões políticas até a busca de prestígio. Freqüentemente estes "motivos" são expressados buscando-se uma justificativa financeira. Contudo, a realidade é que esta intenção tornase obscura devido aos objetivos sociais e políticos envolvidos. Assim, é importante que o responsável por tal serviço reconheça tais objetivos e os esclareça perante a organização que o sustenta. Dessa forma, pode-se pretender um equilíbrio entre a busca de lucros e as obrigações quanto a democratizar a informação.

A área de Biblioteconomia e de Ciência da Informação, assim como outros serviços voltados ao público, devem diferenciar claramente o que é considerado um "serviço núcleo", voltado para a sociedade da informação, e outros serviços ditos "periféricos". Nesse sentido, é imperativo que as instituições façam uma distinção entre aquelas atividades que lhes são fundamentais e outras que são derivadas destas mesmas atividades. Além disso, reconhecer que a cobrança por alguns serviços previamente selecionados pode ser uma solução quando não é possível oferecer modernos serviços de informação utilizando a tecnologia disponível. Já existem estudos que comprovam que a cobrança por serviços de informação é economicamente viável, a fim de se expandirem alguns serviços e se melhorar a qualidade de outros. Este mecanismo faz com que as áreas envolvidas possam determinar seus custos operacionais considerando as condições do mercado consumidor de seus produtos e serviços.

A fim de que se desenvolvam políticas de cobrança por serviços e produtos, os gerentes de sistemas de informação precisam identificar de forma inequívoca os custos destes e o mercado em que este serão oferecidos. As discussões relacionadas com a cobrança têm sido recorrentes e ainda estão divididas entre serem recursos para recuperar custos ou mecanismos para a alocação de recursos.

As organizações sustentadas pelo poder público estão sendo alvo de intensos debates nos países escandinavos, e o ponto mais sensível de tais discussões está relacionado com a imposição de taxas aos usuários e o estabelecimento de mecanismos sólidos e realistas para a definição de valores e preços para serviços e produtos. $\mathrm{O}$ conceito de free or fee para o setor público ainda necessita ser discutido sob a ótica das políticas sócio-econômicas, e à luz da necessidade de reter o espírito do serviço público versus a intenção de trabalhar tais serviços com retorno financeiro.

Esta situação tende a ressaltar a importância dos setores privado e público para uma avaliação conjunta e realizada pelos próprios profissionais envolvidos, assim como para uma contínua atualização e presença na chamada indústria 
da informação, como um dos fatores básicos para o "sucesso" no mundo dos negócios. Os questionários demonstraram que o instrumento de marketing mais efetivo é aquele que acontece boca a boca. Além disto, é igualmente importante o reconhecimento de colegas de campos correlatos como aqueles que estão ligados diretamente com todos os serviços que podem agregar valor dentro da organização. Muitos serviços de informação taxados no setor privado estão trabalhando com nichos de mercado e, para estes, há algum valor no reconhecimento dentro da área de informação. Porém, o real valor repousa na credibilidade que estes podem receber do campo em que atuam. Da mesma maneira, os serviços de informação taxados no setor público devem distinguir em que campo de atuação o reconhecimento de suas atividades e produtos será mais importante, a fim de avaliar seu grau de sucesso.

\section{Produtividade e qualidade}

A informação pode ser considerada tanto um processo como um produto. É também considerada como uma mercadoria de considerável valor econômico, assim como as bibliotecas e os serviços de informação são pontos de transferência de informação.

É de importância vital que os profissionais de informação se concentrem em identificar espaços em que possam atuar de forma pró-ativa, desenvolvendo estratégias e táticas em seus próprios ambientes. As bibliotecas e os serviços de informação precisam orientar-se de forma a garantir uma vantagem competitiva para suas organizações e participar ativamente na busca de informações para os usuários. Os profissionais de informação devem desenvolver produtos de informação de qualidade comprovada, para os quais os usuários não terão dúvida quanto ao pagamento de taxas. Assim, uma tarefa para o profissional da informação é determinar o tipo de informação que uma companhia ou uma organização necessita para ser bem sucedida.

O fato de as atividades de pesquisa estarem sendo trabalhadas de forma cada vez mais globalizada requer decisões rápidas e baseadas em informação relevante e de qualidade. Contudo, a atual crise econômica tem afetado os serviços de informação em todo o mundo, e os países desenvolvidos não são uma exceção. Dessa forma, os setores de informação públicos e privados estão sendo pressionados para o gerenciamento de atividades de informação voltados para atender aos objetivos da organização, os quais também estão sendo avaliados em termos de produtividade e qualidade. As bibliotecas e sistemas de informação voltam a ser avaliados em termos da abrangência e qualidade de seus produtos e serviços. Tais demandas também afetam o trabalho do profissional da informação, que deve desenvolver habilidades para propor e atualizar novos serviços. Novas idéias e estratégias de marketing são imprescindíveis para que se criem novas oportunidades para o oferecimento de serviços e produtos. Assim, a criatividade, o talento e a implementação de novas idéias serão o "capital" do futuro, para o qual a tecnologia será um vetor indispensável. 


\section{Referências bibliográficas}

WARR, K.M. Paying for business information : the role of UK \& European Information brokers \& consultants. Grimsby,UK : Effective Tecnology Marketing, 1994.

WORMELL, I. Critical success factors for feebased information services. Helsinki : NORDINFO, 1996. 134 p. (NORDINFO publications, n. 36).

. Multifuncitional information work new demands for trainning? In: HANCOCKBEAULIEU, M.; PORS, N.O (Ed.) BritishNordic Conference on Library and Information Studies (Copenhagen : 1995). Royal School of Librarianship. p. 45-50.

. The transition of the profession: FID expands professional horizonts. Australian Academic \& Research Libraries, v. 25, n. 2, p. 106-111, June, 1994.

Este trabalho foi apresentado no IFLA/FID Regional Workshop (Abril 1998) - Chile. Tema: Management and use of human resources.

Artigo traduzido, com permissão da autora, por Patricia Zeni Marchiori UFPR/DEBI pzeni@coruja.humanas.ufpr.br)

\section{Irene Wormell}

A Dra. Irene Wormell é especialista em Biblioteconomia, Ciência da Informação, Informática e Cibernética. Suas áreas de pesquisa envolvem a representação do conhecimento voltadas para técnicas de recuperação de informação e de design de bases de dados. Atualmente é Chefe do Centro de Estudos de Infometria.

Para contatos: Royal School of Library and Information Science - Birketinget, DK2300 Copenhagen,Denmark (iw@db.dk)

\section{Title}

Management and Enterprise Skills in the Librarian and Information Scientist's Profession

\section{Abstract}

Information can be considered not only a process but also a product. It is also considered as a merchandise of economic value. Based on this, a research was carried out in organizations or companies which offer and tax information services. After the description of the data, a handbook was elaborated, aiming at helping students and professionals in the information services.

\section{Keywords}

Information - Merchandise; Information - Process; Information Services.

\section{Título}

Habilidades de administrar y emprender en la profesión de Bibliotecario y Cientista de la Información

\section{Resumen}

La información puede ser considerada como un proceso o como un producto. También es considerada como una mercancía de valor económico. Considerando estos aspectos, una pesquisa fue realizada en organizaciones o empresas que ofrecen y tasan servicios de información. A partir de la descripción de los datos, un manual fue elaborado con el objetivo de ayudar a alumnos y a profesionales en la administración y realización de servicios de información.

\section{Palabras-clave}

Información - Mercancía; Información - Proceso; Servicios de Información

Artigo recebido em 10 de dezembro de 1998

Inf.Inf., Londrina, v. 4, n. 1, p. 07-16, jan./jun. 1999 